\title{
IMPROVING PER-PIXEL CLASSIFICATION OF CROP-SHELTER COVERAGE BY TEXTURE ANALYSES OF HIGH-RESOLUTION SATELLITE PANCHROMATIC IMAGES
}

\author{
Claudia Arcidiacono, Simona M.C. Porto
}

\section{Introduction}

The use of high-resolution multispectral images (e.g. Ikonos, EROS, QuickBird) has been found to improve the recognition of man-made features in comparison to the utilization of RGB images or low resolution multispectral ones [Lee 2003; Kim 2006; Agüera 2006; Mayunga 2007; Agüera 2009].

In previous works [Arcidiacono 2010c; Arcidiacono 2010d; Arcidiacono 2012] the results of a classification methodology aiming at the automated recognition of crop shelters (i.e., greenhouses, tunnels, and vineyard pergolas) from high-resolution multi-spectral satellite images were presented. This methodology involved the use of automated per-pixel recognition methods and texture analyses. In detail, ten texture analyses were carried out by applying methods based on Grey Level Co-occurrence Matrix (GLCM) [Haralick 1973] and Grey Level Difference Vector (GLDV). Ten classifications were performed by combining the values provided by every texture analysis with RGB-band information. Such a technique was often used in classification procedures regarding manmade objects [Lee 2003; Wang 2004; Puissant 2005].

The results of the accuracy assessment carried out for each classification showed analogous values to those obtained by other researchers who applied a similar methodology to a region of Spain characterized by a significant presence of crop-shelter settlements [Agüera 2008]. Moreover, in that previous study, Arcidiacono and Porto [2010c; 2010d; 2012] defined an index that made it possible to assess the overestimation of crop-shelter coverage obtained from each classification by comparing the number of

Paper received 30.05.2011; accepted 15.10.2011

Claudia ARCIDIACONO, associate professor, carcidi@unict.it, SiMONA M.C. PoRTo, Phd, siporto@unict.it, University of Catania, Department of Agri-food and environmental systems management, Section: Building and Land Engineering, via S. Sofia 100 - 95123 Catania (Italy). Tel. 0039.0957147576, fax 0039.0957147600.

All authors of this research paper have equally participated in the planning, execution, and analysis of this study. pixels incorrectly classified as crop shelters with the whole number of pixels identifying crop shelters. That index $\mathrm{R}$ was used to select a set of textures to perform a further classification by combining these texture values with RGB-band information. The obtained classification was characterized by crop-shelter areas having a high pixel density despite the slight increase of classification errors in the background, which could be reduced by using filters based on shape and dimension of wrongly classified pixel clusters. The application of the methodology makes it possible to reduce the post-processing operations to be performed on the classification images which, on one hand, are needed to achieve a higher pixel density in crop-shelter areas and, on the other hand, generally determine an overestimation of areas classified as crop shelters.

The objective of this paper is to assess the accuracy of crop-shelter coverage classification achieved by combining texture information obtained from highresolution panchromatic images $(0.6 \mathrm{~m})$ with spectral information of high-resolution RGB bands $(2.4 \mathrm{~m})$. In detail, the aim is to verify whether the use of textures obtained from high-resolution panchromatic images contributes to improve the classification quality achieved by applying the methodology defined in the previous study. There, in fact, classifications were performed by using information contained in 'degraded' panchromatic layers, i.e., having a geometric resolution reduced in comparison with the initial one. To allow the comparison between the results of this paper with those previously found, the methodology was applied to the same sample area of the study area located in south-eastern Sicily (Italy).

\section{Materials and methods}

The water-fall model of the methodology adopted in this study is showed in Figure 1. A more detailed description can be found in Arcidiacono and Porto, [2010c; 2010d; 2012].

The described methodology was applied to a study area located in south-eastern Sicily, highly representative of the territorial use as intensive agricultural areas 


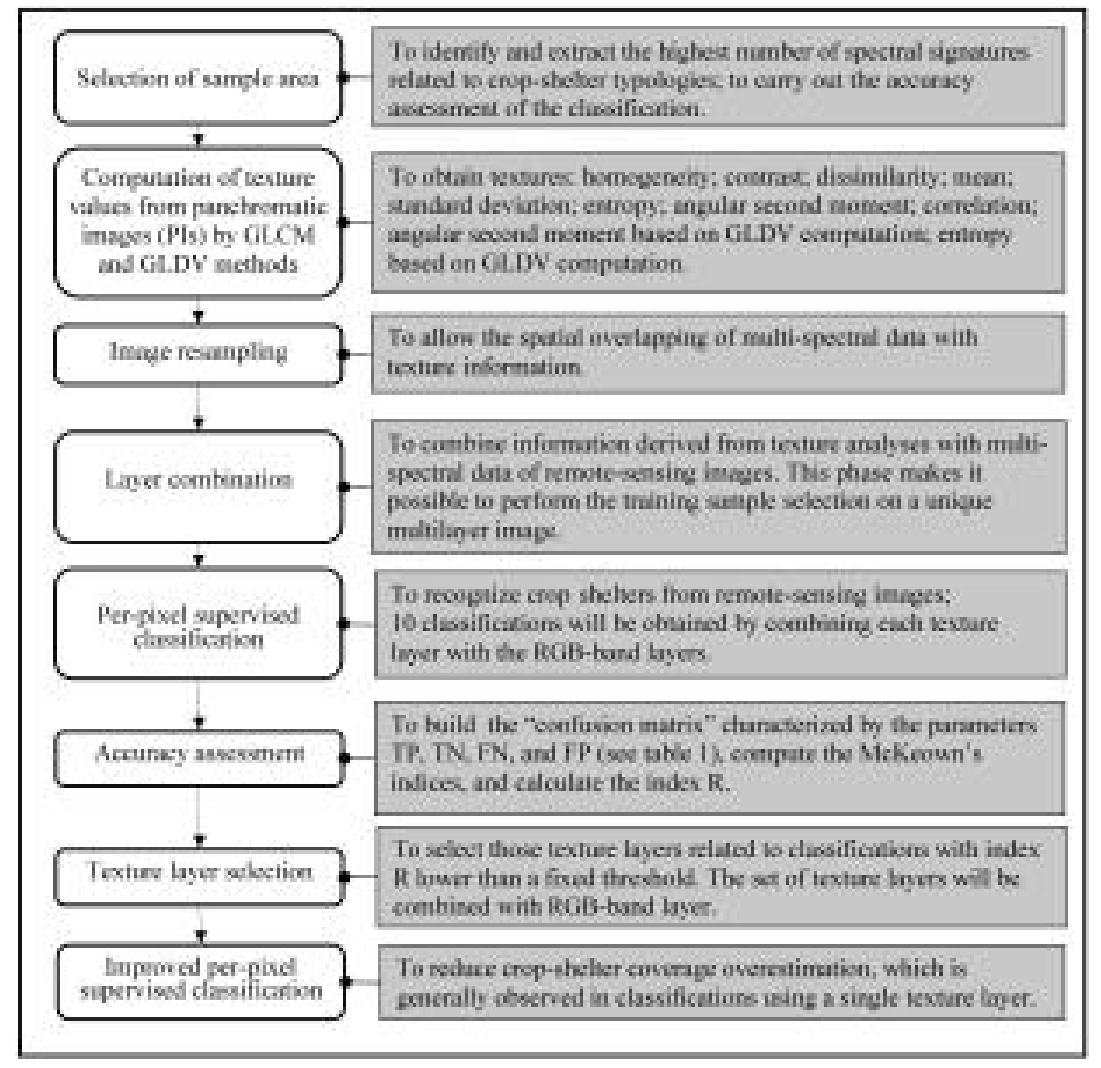

Fig. 1 - Water-fall model of the classification methodology.

for protected cultivation. Table 1 summarizes the characteristics of the areas under study and the imagery used.

The panchromatic images were resampled to 128 grey levels. Moreover, the geometric resolution of the RGB multi-spectral bands was increased from $2.4 \mathrm{~m}$ to $0.6 \mathrm{~m}$ to enable the overlapping of their spatial information with that of the panchromatic images (Fig. 2 ). The computation of the values concerning the 10 texture typologies was carried out by developing a specific application using the compiler Visual $\mathrm{C}++$ 2008 express edition within an integrated environment of software programming (IDE) free distributed by Microsoft. The following textures were computed:

Homegeneity (Ho):

$$
\sum_{i=1}^{N-1} \sum_{j=1}^{N-1} \frac{P(i, j)}{1+(i-j)^{2}}
$$

Contrast (Con):

$$
\sum_{i=1}^{N-1} \sum_{i=1}^{N-1} P(i, j) \times(i-j)^{2}
$$

Dissimilarity (Di):

$$
\sum_{i=1}^{N-1} \sum_{j=0}^{x-1} P(i, j) \times|i-j|
$$

Mean (Me):

$$
\sum_{i=1}^{N} \sum_{j=1}^{K-1} i \times P(i, j)
$$

Standard deviation (SD):

$$
\left[\sum_{i=1}^{N} \sum_{i=1}^{N-1} P(i, j) \times(i-M E A i)^{2}\right]^{1 / 2}
$$

Entropy (En):

$$
\sum_{i=1}^{N-i} \sum_{j=1}^{K-1}-P(i, j) \times \log _{0}(P(i, j))
$$

Angular Second Moment (ASM):

$$
\sum_{i=1}^{N-1} \sum_{i=1}^{X-1} P(i, j)^{2}
$$

Correlation (Cor):

$$
\sum_{i=1}^{N-1} \sum_{=1}^{K-1} \frac{P(i, j) \times(i-M E A i) \times(j-M E A j)}{S T D i \times S T D j}
$$

GLDV- Angular Second Moment - (GLDV-ASM):

$$
\sum_{i=1}^{N} V(k)
$$

GLDV-Entropy (GLDV-En)):

$$
\sum_{k}^{N-1}(-V(k)) \times \log (V(k))
$$

where $N$ represents the grey levels, $P$ is the GLCM normalized and simmetric having dimension $N \times N, V$ is the GLDV normalized, $P(i, j)$ is the $(i, j)$-th element of the GLCM, and $V(k)$ is the $k$-th element of GLDV.

The window size used to compute the co-occurrence matrix was fixed to $19 \times 19$ because this dimension was appropriate for the average width of green- 
Siuch area: $=2113$ ha: rectangular: NW vertex: 4090119.8 N. 445745.6 E; SE vertex: $4085471.0 \mathrm{~N}, 450260.0$ E; zone 33 UTM, WGS84.

Sample area: $\approx 285$ ha $(4400 \times 1817$ pixels $)$.

Cantrol areas: $\$ 95$ ha each $(1782 \times 1508$ pixels $)$.

Satelitie Diginal imoges: Quick Bird, Ortho-Ready Standard Level; year 2006; multi-spectral bands (Red, Green, Blue and NIR) with a $2.4 \mathrm{~m}$ resolution; panchromatic band with a 0.6 m resolution.

Vector Digital Image: thematic layer related to crop-shelter coverage of the considered area, obtained by visual recognition of satellite images.

TABLE 1 - The characteristics of the areas under study and the imagery.

house span in relation to the image resolution. To obtain the average value of each texture measure, displacement vectors in four directions $\left(0^{\circ}, 45^{\circ}, 90^{\circ}\right.$, $135^{\circ}$ ) with a spatial distance of 1 pixel were used. For each pixel of the panchromatic image, the co-occurrence matrix allowed the computation of the values of the 10 texture typologies analyzed.

Since the resolution of the study area image was far higher $(7547 \times 7776$ pixels $)$ than that used in the previous study $(1888 \times 1945$ pixels $)$, the computation of the 10 textures was carried out only in the sample area and the two control areas, rather than in the whole study area. The 10 texture layers were then overlapped with those related to the RGB bands of the sample area and the control areas. In this study only the analyses related to the sample area are reported.

The previously defined training sample was used in order to extract the spectral signatures of crop shelters [Arcidiacono 2010c; Arcidiacono 2010d, Arcidiacono 2012]. Within this sample of signatures also a number of parcels representative of 'uncovered' crop shelters, i.e., lacking in the covering film and identifiable by their structure through the visual recognition of images, was included. The histograms of the selected spectral signatures showed a nearly-normal distri- bution, therefore the Maximum-Likelihood classifier (MLC) was used. In detail, 10 classifications were performed by combining each texture layer with the RGB-band layers. The classifications were carried out by using the commercial software Leica Erdas Imagine $\AA$.

The thematic layers obtained from the classifications were then recoded by assigning the value 1 to the 39 classes of crop shelters and the value 0 to the remaining classes. This recoding was necessary to obtain two distinct classes: the first one containing the set of classes related to crop shelters; the other one providing information on background.

The accuracy assessment was carried out by selecting ground control points (GCPs) at an equal interval over a space of $5 \mathrm{~m}(87,776$ points $)$, according to a systematic sampling approach. Lower values of the grid size did not improve accuracy assessment values (data not shown).

To perform the accuracy assessment, the thematic layer related to crop-shelter coverage was obtained by visual recognition of satellite images. The thematic layer of crop-shelter coverage, composed of the feature classes representing the parcels covered with greenhouses, tunnels, or vineyard pergolas, as well as the thematic layer containing the GCPs were produced in vector format by using a GIS software. Afterwards, each GCP was assigned to the crop-shelter class, or else to the background class, by carrying out the topographic overlay of the GCP vector layer with the crop-shelter coverage one. In detail, two spatial queries were performed in order to select those GCP located within crop-shelter polygons and GCPs outside them (background). Two different attribute values were assigned to the GCPs, i.e., 1 to those located within crop-shelters and 0 to those outside them. Every attribute value was compared with the corresponding pixel value in the classified image in order to produce the error matrix for each of the 10 classifications. This error matrix was then used to compute

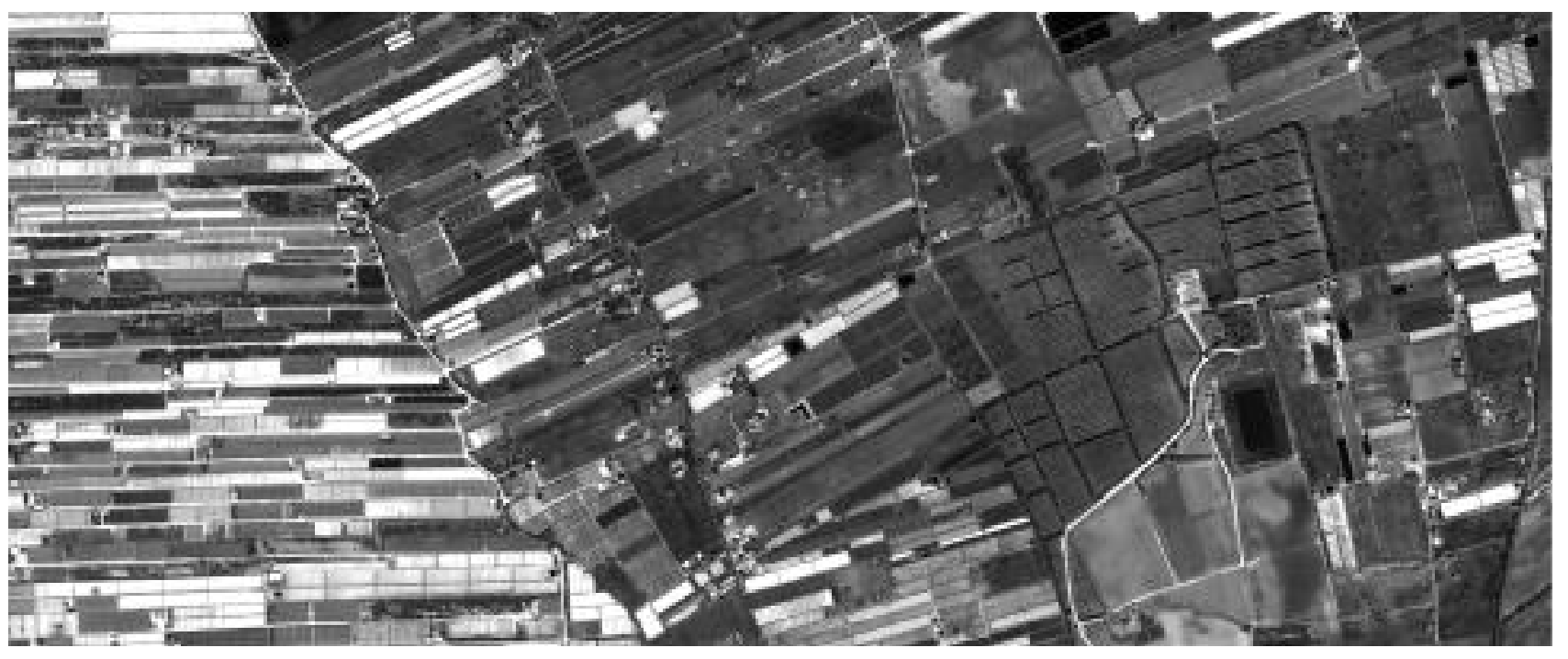

Fig. 2 - Panchromatic images of the sample area. 
the indices defined by McKeown (1999) and the R index [Arcidiacono 2010c; Arcidiacono 2010d; Arcidiacono 2012]. Table 2 summarizes parameters and indices computed in this study.

Another analysis was carried out to evaluate the accuracy of the contour detection. In detail, for each of the 450 parcels $i$ located in the sample area, the fraction of crop-shelter parcel area $\left(\varepsilon_{i}\right)$ which extends beyond the parcel boundary was computed by following the steps defined below:

- Computation of the pixel majority count (i.e., count of the pixels having the value 1 within the considered parcel and which, therefore, were classified as 'greenhouse') and the pixel minority count (i.e., count of the pixels having the value 0 within the considered parcel and which, therefore, were classified as 'background') [Erdas 2003].

\begin{tabular}{|c|c|}
\hline Aсномум & Discrumon \\
\hline TP & $\begin{array}{l}\text { True Positive: mumber of pixels corresponding to } \\
\text { GCPs identifying crop-sbelter coverage, comectly } \\
\text { classified as crop shelters. }\end{array}$ \\
\hline $\mathrm{TN}$ & $\begin{array}{l}\text { True Negative: number of pixels corresponding to } \\
\text { GCP, uhich do not identify erop-shelter conerage, } \\
\text { correclly classified as background }\end{array}$ \\
\hline $\mathrm{FN}$ & $\begin{array}{l}\text { Fulse negative: number of pixels corresponding to } \\
\text { GCPs identifying croposhelter coverage, incorrectly } \\
\text { classifest as bakkground }\end{array}$ \\
\hline $\mathrm{FP}$ & $\begin{array}{l}\text { False positive number of phels correspotbling to } \\
\text { GCPs which do not idcntify crop-shelter coverage. } \\
\text { incorrectly classified as crop thelters }\end{array}$ \\
\hline \multirow{3}{*}{ BF } & Branching factor: \\
\hline & $\frac{F P}{T P}$ \\
\hline & $\begin{array}{l}\text { It provides information on the error made by the } \\
\text { classifier in distinguishing crop shelters from } \\
\text { background. }\end{array}$ \\
\hline \multirow{3}{*}{ MF } & Miss factor: \\
\hline & 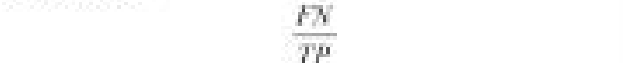 \\
\hline & $\begin{array}{l}\text { It provides information on classifier ability to prodace } \\
\text { a derse crop-shelter concrage. i.e., having fer smpey } \\
\text { islands. }\end{array}$ \\
\hline \multirow[b]{3}{*}{ GDP } & Greenhouse detestion percentuge: \\
\hline & $100 \times \frac{T P}{T P+F N}$ \\
\hline & $\begin{array}{l}\text { It makes it possible to evaluate the ability of the } \\
\text { classifier to identify cropushelter arcas, yet it does not } \\
\text { provide infomatice on its efficiency in distinguishing } \\
\text { crop-shelter coverage from background. }\end{array}$ \\
\hline \multirow{4}{*}{ QP } & Quality percantage: \\
\hline & $100 \times \frac{7 P}{00}$ \\
\hline & $\frac{T P+F N+F P}{4 P}$ \\
\hline & $\begin{array}{l}\text { It provides informition on slassifier efictency in } \\
\text { distinguishing crop-shelter coverage from } \\
\text { background. }\end{array}$ \\
\hline \multirow[b]{2}{*}{$\mathbf{R}$ index } & $R=1+\frac{F P}{F n}$ \\
\hline & $\begin{array}{l}\text { It assesses the everestimation of erop-shelter } \\
\text { conerage by comparing the number of pixels } \\
\text { incarrectly classified as crop sheliers (FP) with the } \\
\text { whole number of pixels identifying crop shelters } \\
\text { (TP+FN) }\end{array}$ \\
\hline
\end{tabular}

TABLE 2 - Parameters and indices computed in this study.
- Computation of the area related to the pixel majority count $\left(\mathrm{A}_{1}\right)$ and to the pixel minority count $\left(\mathrm{A}_{2}\right)$ by multiplying each count for the considered image resolution (i.e., $2.4 \mathrm{~m}$ or $0.6 \mathrm{~m}$ ).

- Computation of the contour area $\mathrm{A}_{C i}$ as:

$$
\mathrm{A}_{\mathrm{C} i}=\left(\mathrm{A}_{1 i}+\mathrm{A}_{2 i}\right)-\mathrm{A}_{i}
$$

where $\mathrm{A}_{i}$ is the area of each parcel measured in the crop-shelter vector layer.

- Computation of the theoretic overall number $\mathrm{n}_{\mathrm{T} i}$ of the pixels which constitutes each parcel boundary. Such number was computed by producing a raster layer of crop-shelter parcel boundaries from the vector one. In detail, a specific layer was produced having the same resolution of the thematic classification layer.

- For each crop-shelter parcel, computation of the overall number $\mathrm{n}_{\mathrm{G} i}$ of the contour pixels having value 1 , i.e., belonging to the crop-shelter class. Such a number was computed by overlapping the thematic layer containing the parcel boundaries with the thematic classification layer.

- Computation of the ratio between $\mathrm{n}_{\mathrm{G} i}$ and $\mathrm{n}_{\mathrm{T} i}$. This number quantifies the real fraction of pixels belonging to the contour classified as crop shelters.

- Computation of the fraction of the crop-shelter parcel area $\left(\varepsilon_{i}\right)$ which extends beyond the parcel boundary, by the following relation:

$$
\varepsilon_{i}=\left(\mathrm{A}_{\mathrm{C} i} \times \mathrm{n}_{\mathrm{G} i} / \mathrm{n}_{\mathrm{T} i}\right) / \mathrm{A}_{i}
$$

The average, the maximum, the minimum, and the standard deviation values of the errors $\varepsilon_{i}$ in crop-shelter contour detection were computed for the whole sample area.

The described procedure was followed for the computation of the areas $\varepsilon_{i}$ obtained from the classifications carried out by using resampled panchromatic images (i.e., resolution of $2.4 \mathrm{~m}$ ) and native-resolution panchromatic images (i.e., resolution of $0.6 \mathrm{~m}$ ).

\section{Results and discussion}

Table 3 shows the values of McKeown's indices and the $\mathrm{R}$ index computed to assess the accuracy of the classifications obtained using different combinations of information from RGB and texture layers.

The results related only to the RBG-band layers confirm once more the findings of previous studies [Arcidiacono 2008; Arcidiacono 2010c; Arcidiacono 2010d]. In detail, though crop-shelter classification is accurate $(\mathrm{GDP}=85.71 \%)$ and there are few empty islands inside crop-shelter coverage $(\mathrm{MF}=0.17)$, the value of the index $\mathrm{BF}$ is equal to 0.22 . This resulted in misclassification of some soil types as crop shelters.

In general, the main objective of the classification affects the choice of the texture. If it is to minimize the number of pixels belonging to the background wrongly classified as crop shelters (low BF and then high QP), i.e., to reduce the 'salt-and-pepper' effect in the background, then the texture parameter 'entropy' fulfils the objective requirements, in this case study (Tab. 3). On 


\begin{tabular}{|c|c|c|c|c|c|c|}
\hline \multicolumn{2}{|r|}{ LAYER COMBINATION } & \multirow{2}{*}{$\mathrm{BF}$} & \multirow{2}{*}{ MF } & \multirow{2}{*}{ GDP } & \multirow{2}{*}{$\mathrm{QP}$} & \multirow{2}{*}{ R } \\
\hline RGB - band & Textures & & & & & \\
\hline $\mathrm{R}, \mathrm{G}, \mathrm{B}$ & . & 0.22 & 0.17 & 85.71 & 72.07 & 1.19 \\
\hline $\mathrm{R}, \mathrm{G}, \mathrm{B}$ & Homogeneity & 0.22 & 0.20 & 83.59 & 70.83 & 1.18 \\
\hline $\mathrm{R}, \mathrm{G}, \mathrm{B}$ & Contrast & 0.17 & 0.22 & 82.07 & 71.92 & 1.14 \\
\hline $\mathrm{R}, \mathrm{G}, \mathrm{B}$ & Dissimilarity & 0.18 & 0.23 & 81.39 & 70.91 & 1.15 \\
\hline $\mathrm{R}, \mathrm{G}, \mathrm{B}$ & Mean & 0.15 & 0.25 & 80.06 & 71.24 & 1.12 \\
\hline $\mathrm{R}, \mathrm{G}, \mathrm{B}$ & Standard deviation & 0.21 & 0.16 & 86.11 & 72.99 & 1.18 \\
\hline R, G, B & Entropy & 0.14 & 0.22 & 82.05 & 73.33 & 1.12 \\
\hline $\mathrm{R}, \mathrm{G}, \mathrm{B}$ & Angular Second Moment & 0.16 & 0.23 & 81.45 & 72.13 & 1.13 \\
\hline R, G, B & Correlation & 0.15 & 0.19 & 83.76 & 74.67 & 1.12 \\
\hline $\mathrm{R}, \mathrm{G}, \mathrm{B}$ & GLDV-Angular Second Moment & 0.21 & 0.19 & 83,71 & 71.18 & 1.18 \\
\hline $\mathrm{R}, \mathrm{G}, \mathrm{B}$ & GLDV-Entropy & 0.21 & 0.19 & 83.77 & 71,09 & 1.18 \\
\hline R, G, B & Contrast, Mean, Entropy, Angular Second Moment, Correlation & 0.15 & 0.13 & 88.42 & 78.16 & 1.13 \\
\hline
\end{tabular}

TABLE 3 - Indices following McKeown [1999] and R index [Arcidiacono 2010c; Arcidiacono 2010d; Arcidiacono 2012] computed for classifications obtained using different combinations of information from RGB and texture layers, for the sample area.

the contrary, if the main classification goal is to minimize the pixels belonging to crop-shelter coverage wrongly classified as background (low MF and then high GDP), i.e., to reduce empty islands, then the information derived from the texture parameter 'standard deviation' results more suitable to the aim (Tab. 3).

In this study, the use of the $\mathrm{R}$ index aimed at guiding the choice of the best combination of RGB layer with textures in order to achieve the lowest value of MF, yet having a value of BF very close to the minimum one. The experiences carried out in this study confirmed, in fact, that the improvement of crop-shel- ter classification can be achieved by combining the information derived from a set of textures with that of RGB bands. In detail, in order to reduce the number of FP (i.e., the 'salt-and-pepper' effect) the texture layers characterized by an $\mathrm{R}$ value lower than a threshold value, equal to 1.14 , were selected. This threshold value establishes that the pixel number responsible for the 'salt-and-pepper' effect (FP) keeps below the $14 \%$ of the GCPs selected within crop shelters (i.e., $\mathrm{FP}<14 \%(\mathrm{TP}+\mathrm{FN})$.

In this analysis, the combination satisfying this condition included the information related to the textures

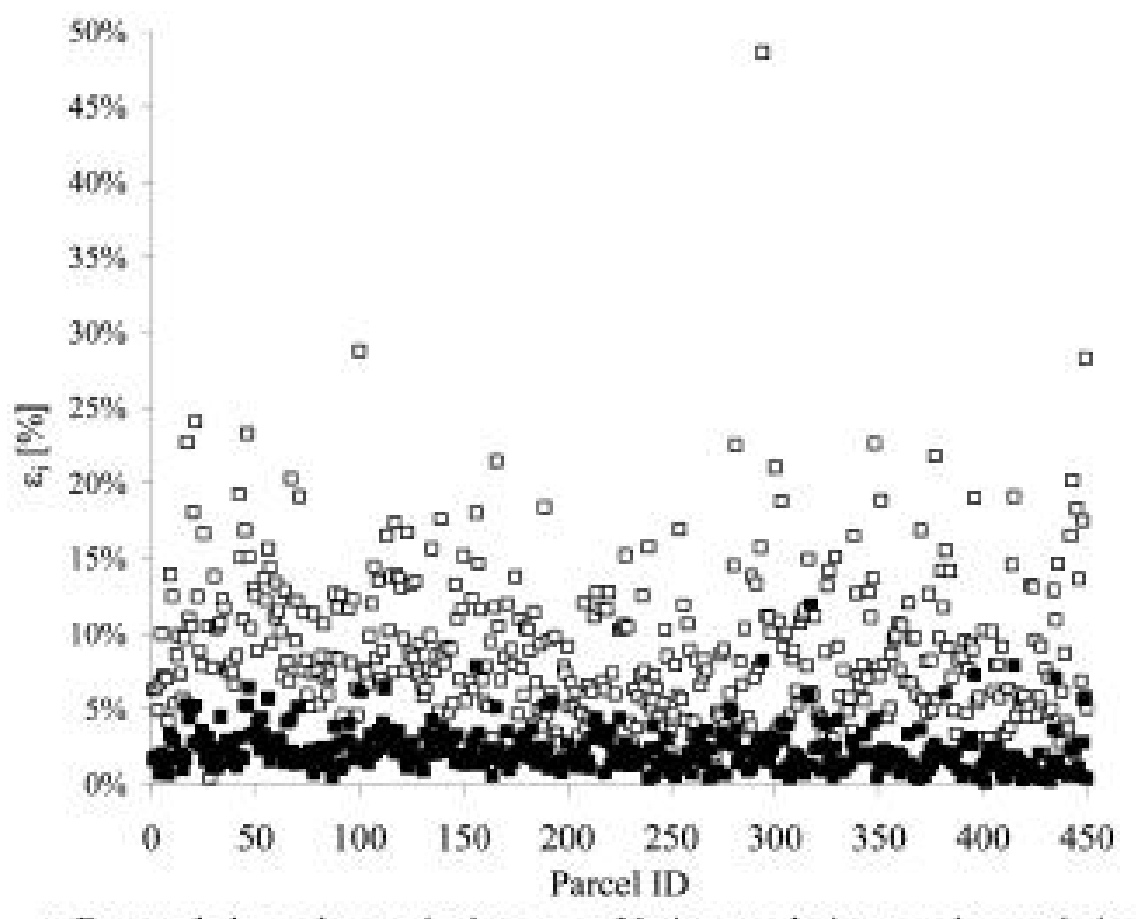

- Resampled panchromatic images - Native-resolution panchromatic images

Fig. 3 - Comparison between the accuracy of contour detection of the classification performed by using resampled panchromatic images (i.e., resolution of $2.4 \mathrm{~m}$ ) and that of the classification carried out by using panchromatic images with native resolution (i.e., resolution of $0.6 \mathrm{~m}$ ). 
Con, Me, En, ASM, and Cor, as shown in Table 3.

The comparison between the combinations RGBCon-Me-En-ASM-Cor and RGB-En, which has the minimum value of the index $\mathrm{R}$, showed good results: reduction of $\mathrm{MF}$ index from 0.22 to 0.13 ; improve-

a)

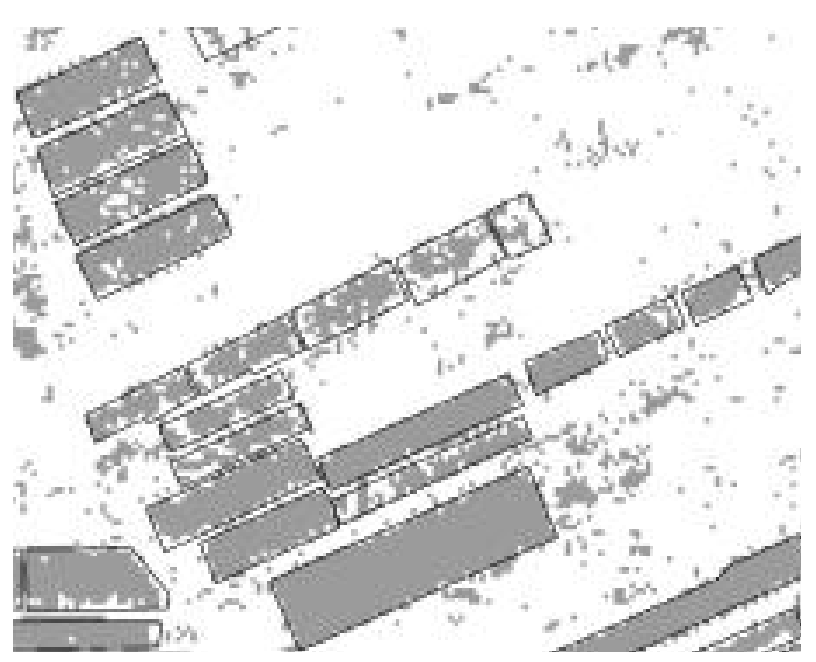

b)

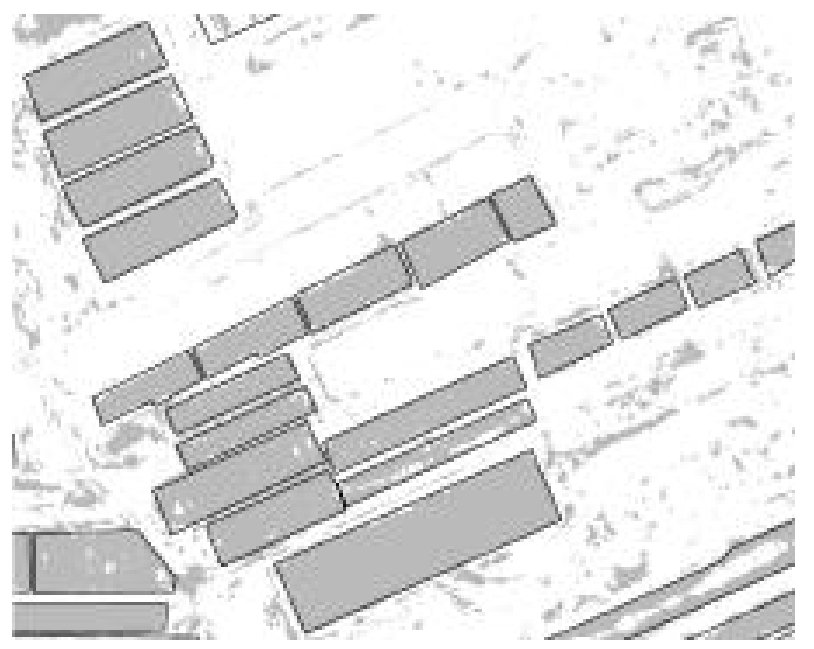

c)

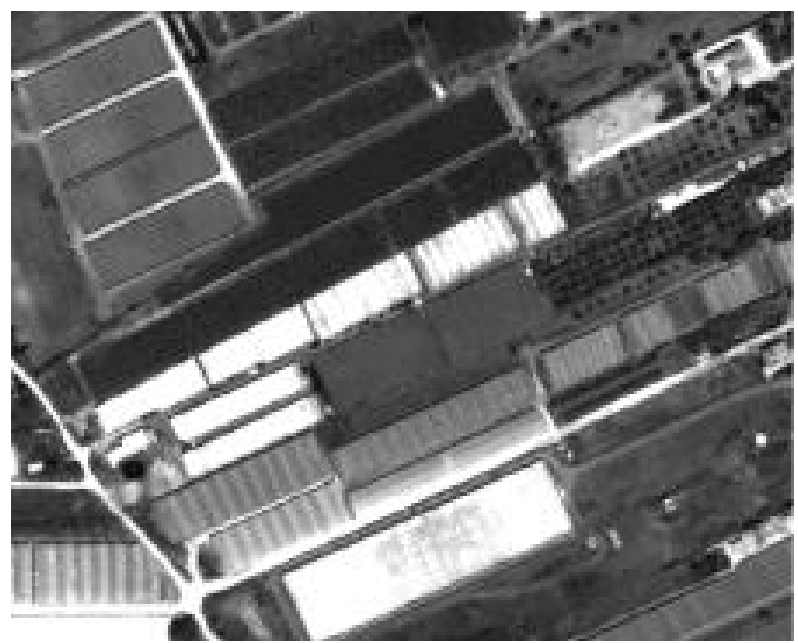

Fig. 4 - Comparison between the accuracy of the classification carried out by using panchromatic images with a native resolution (0.6 m) (a) and that performed by using resampled panchromatic images (2.4 m) (b). Panchromatic image (c). ment of both GDP and QP indices which still have a low ratio $\mathrm{R}$ equal to 1.13 ; very slight worsening of the $\mathrm{BF}$ index which increases by 0.01 .

The comparison between the combination RGBCon-Me-En-ASM-Cor and that obtained in the previous studies [Arcidiacono 2010c; Arcidiacono 2010d; Arcidiacono 2012], showed improvement of the indices MF $(+0.02)$ and GDP $(+1.43 \%)$, and a decrease of the indices BF (-0.02) and QP (-1.13\%). Therefore, the results achieved in this study showed that the use of textures computed from high-resolution panchromatic images improves crop-shelter pixel density despite a worsening of the background detection, which could be reduced by using filters based on shape and dimension of wrongly classified pixel clusters. This result allows the reduction of post-processing operations to be performed on the classification images to achieve a higher pixel density in crop-shelter areas. These operations can be performed by neighbourhood processing methods [Gonzalez 2002] with the aim to enhance and restore crop-shelter areas. Some of these operations were used in a previous work [Arcidiacono 2010b] carried out to recognize crop-shelter coverage by RGB aerial images.

Figure 3 shows the comparison between the accuracy of contour detection of the classification performed by using resampled panchromatic images (i.e., resolution of $2.4 \mathrm{~m}$ ) and that of the classification carried out by using panchromatic images with a native resolution (i.e., resolution of $0.6 \mathrm{~m}$ ). Moreover, Table 4 reports the average, the maximum, the minimum, and the standard deviation values of errors $\varepsilon_{\mathrm{i}}$ in cropshelter contour detection computed for the whole sample area in the two cases.

A very high accuracy in contour detection was achieved by using panchromatic images with native resolution. The error on contour detection reduced by about $6.7 \%$ on average, with minimum and maximum values which ranged between $0.3 \%$ and $36.7 \%$.

Figs. $4 \mathrm{a}$ and $4 \mathrm{~b}$ report an excerpt of the crop-shelter thematic maps obtained by carrying out the two classifications. Generally, the detection of crop shelters obtained in this study was far more accurate than the one related to the use of resampled panchromatic images. Moreover, an improvement of the recognition of 'uncovered' greenhouses is achieved. In fact, the

\begin{tabular}{|c|c|c|}
\hline \multirow{2}{*}{$\begin{array}{l}\text { PARAMEIER } \\
\text { STATISTICS }\end{array}$} & \multicolumn{2}{|c|}{$\begin{array}{l}\text { PANCHROMATIC } \\
\text { LAYER RESOCUTION }\end{array}$} \\
\hline & Degraded & Narive \\
\hline & Error $[\%]$ & Error $[\%]$ \\
\hline Mean & 8.95 & 2.23 \\
\hline Max & 48.64 & 11.95 \\
\hline Min & 0.47 & 0.18 \\
\hline STD & 5.01 & 1.41 \\
\hline
\end{tabular}

TABle 4 - Average, maximum, minimum, and standard deviation values of errors $\varepsilon$, in crop-shelter contour detection computed for the whole sample area. 
four 'uncovered' greenhouses in the top left corner of the Figure 4c show a higher pixel density and a better contour detection in Figure $4 b$ than in Figure 4a.

The results obtained in this study highlight how the use of textures computed from high-resolution panchromatic images can be suitable to improve the identification of parcel contours. Since a relevant computational burden is required to texture computation, the use of the proposed methodology is more adequate for the construction of large-scale maps $(\geq 1: 5000)$ in which, besides inserting the features related to crop shelters, the definition of parcel contours with a higher precision would be required. These contours, in fact, if correctly delineated could make it possible to add further information to the drawn map, such as, for instance, information related to paths for pedestrian and/or vehicles recognizable between crop shelters.

The classifications obtained by using the proposed methodology could be used to produce thematic maps of crop-shelter coverage suitable to analyze its variation over time within planning tools regarding land use, and landscape and environmental preservation [Arcidiacono 2010a; Picuno 2011]. Finally, the methodology proposed in this study can be adopted for the extraction and vectorization of classified cropshelter contours. This would be in accordance with the actual international research hints [Agüera 2009] which indicate in the use of high-resolution panchromatic images possible improvements to obtain contours corresponding to only one crop shelter.

\section{Conclusions}

In this paper the results of a classification methodology aiming at the improvement of automated recognition of crop shelters from high-resolution multispectral satellite images are presented.

The accuracy assessment of these classifications was performed by using McKeown's indices. The defined index $\mathrm{R}$ was used to select that texture layer combination which improves crop-shelter pixel density despite a worsening of the background detection. Such errors could be reduced by using filters based on shape and dimension of wrongly classified pixel clusters.

The results of this work were compared with those found in a previous research carried out in the same sample area located in south-eastern Sicily (Italy). They proved that the use of texture layers obtained from native-resolution panchromatic images contributes to improve the crop-shelter classification quality (i.e., MF and GDP indices) in comparison to that of classifications performed by using information contained in 'degraded' panchromatic layers. A further analysis carried out to evaluate the accuracy of the contour detection, showed that the fraction of crop-shelter parcel areas which extends beyond the parcel boundary reduces by $6.7 \%$ on average, with a maximum decrease of $36.7 \%$.

\section{References}

Agüera F., Aguilar M.A., Aguilar F.J., Detecting greenhouse changes from QuickBird imagery on the Mediterranean coast, Int. J. Remote Sens., 2006, 27(21), 47514767.

Agüera F., Aguilar F.J., Aguilar M.A., Using texture analysis to improve per-pixel classification of very high resolution images for mapping plastic greenhouses, ISPRS Journal of Photogrammetry \& Remote Sensing, 2008, 63, 635-646.

Agüera F., Liu J.G., Automatic greenhouse delineation from QuickBird and Ikonos satellite images, Computers and Electronics in Agriculture, 2009, 66, 191-200.

Arcidiacono C., Porto S.M.C., Image Processing for the Classification of Crop Shelters, ISHS Acta Horticulturae, 2008, 801, 309-316.

Arcidiacono C., Porto S.M.C., A model to manage cropshelter spatial development by multi-temporal coverage analysis and spatial indicators, Biosystems Engineering, 2010a, 107 (2), 107-122.

Arcidiacono C., Porto S.M.C., Classification of crop-shelter coverage by remote-sensing images: a compendium of experiences and findings, Journal of agricultural engineering, 2010b, 3, 1-11.

Arcidiacono C., Porto S.M.C., L'uso di immagini satellitari ad alta risoluzione per la classificazione automatica di apprestamenti di protezione delle colture (1a parte), 2010c, Colture Protette, 10/11, 70-73.

Arcidiacono C., Porto S.M.C., L'uso di immagini satellitari ad alta risoluzione per la classificazione automatica di apprestamenti di protezione delle colture (2a parte), 2010d, Colture Protette, 12, 88-92.

Arcidiacono C., Porto S.M.C., Pixel-based Classification of High-Resolution Satellite Images for Crop-Shelter Coverage Recognition, 2012, in press on Acta Horticulturae, IHC18 Advances in Ornamentals, Landscape, and Urban Horticulture.

Erdas Field Guide ${ }^{\mathrm{TM}}$, Erdas Inc., 2003, Atlanta (Georgia).

Gonzalez R., Wood R., Digital imagine processing, Prentice Hall, Second edition, 2002, Upper Saddle River, New Jersey.

Haralick R.M., Shanmugan K., Dinstein I., Textural features for image classification, IEEE Transactions on Systems, Man and Cybernetics, 1973, 3(6), 610-621.

Kim T., Lee T.Y., Kim K.O., Semiautomatic building line extraction fromIkonos images through monoscopic line analysis, Photogramm. Eng. Remote Sens, 2006, 72, 541-549.

Lee S.D., Shan J., Bethel J., Class-guided buildings extraction from Ikonos imagery, Photogramm. Eng. Remote Sens, 2003, 69 (2), 143-150.

Mayunga S.D., Coleman D.J., Zang Y., A semi-automated approach for extracting buildings from QuickBird imagery applied to informal settlement mapping, Int. J. Remote Sens., 2007, 1-15.

McKeown D.M., Cochran S.D., Ford S.J., McGlone J.C., Shufelt J.A., Yocum D.A., Fusion of HYDICE Hyperspectral Data with Panchromatic Imagery for Cartographic Feature Extraction, IEEE Transactions on Geoscience and Remote Sensing, 1999, 37 (3).

Picuno P., Tortora A., Capobianco R.L., Analysis of plasticulture landscapes in Southern Italy through remote sensing and solid modelling techniques, Landscape and urban planning, 2011, 100, 45-56.

Puissant A., Hirsch J., Weber C., The utility of texture 
analysis to improve per-pixel classification for high to very high spatial resolution imagery, International Journal of Remote Sensing, 2005, 26 (4), 733-745.

Wang L., Sousa W.P., Gong P., Biging S., Comparison of IKONOS and QuickBird images for mapping mangrove species on the Caribbean coast of Panama, Remote Sensing of Environment, 2004, 91 (3-4), 432-440.

\section{SUMMARY}

Actual research challenges in automated recognition of crop shelters regard, among other issues, the accuracy of classification, contour detection and typology identification. In this field the use of high-resolution multispectral images has been found to improve the feature recognition in comparison to RGB images or low resolution multispectral ones.

As for classification methodologies, per-pixel and object-oriented ones offer different tools to cope with image recognition and feature extraction.

In this study, to improve the classification of cropshelter coverage, the per-pixel method was applied to high-resolution multispectral images, coupled with a texture analysis of high-resolution panchromatic images. In detail, the results of the classification accuracy assessment achieved by the use of native high-resolution panchromatic images and RGB-band images resampled accordingly, were compared with those found in a previous study in which panchromatic images degraded to the RGB-band image resolution were used.

The results show that the proposed methodology is suitable to improve crop-shelter classification quality and contour detection of parcels.

Keywords: greenhouse, GIS, texture, accuracy assessment. 